\title{
The importance of Chinese National Opera practice in College Vocal Music Teaching
}

\author{
Chunmeng Wang ${ }^{1, \text { a }}$ \\ ${ }^{1}$ college of art, Binzhou University, Binzhou 256600, China \\ awangcm315@126.com
}

Keywords: Chinese national opera; practice; national vocal music; teaching; importance

Abstract. In the history of the development of Chinese national vocal music, Chinese National Opera occupies the extremely critical position. Although China's national opera and national choral music are different, but there are a lot of similarities between the two, they promote each other in the process of progress, mutual integration. However, in the national vocal music teaching process, Chinese National Opera practice is not reflected, not the promotion of national vocal music and national vocal music teaching system is not perfect, lack of awareness and understanding of China's national opera, the national vocal music teaching not enough attention, resulting in a decline in Colleges and universities of China National Vocal Music status, serious the influence of the development of our national vocal music. Therefore, the significance of the practice of Chinese national opera for the national choral music teaching in colleges and universities is self-evident. Strengthening national vocal music teaching in colleges and universities.

In the process of the national vocal music teaching in our country, the National Opera and it is inextricably linked, the two mutually dependent on each other, common development and common prosperity [1]. The teaching of national raucous music is not only a part of the teaching work, but also the inheritance and development of Chinese National Opera culture. But now, China's national vocal music teaching effect is not good, cannot be really into the practice of national opera into the national vocal music teaching. Therefore, in order to promote the work of the vocal music teaching in Universities for nationalities should be started, China National Opera in the proper way to penetrate the national vocal music teaching, improve the teaching quality of universities and teachers for the national vocal music teaching, promote students to learning and understanding of national vocal music, through the development of national opera works of art appreciation and taste, let the students expressed deep feelings of national vocal music in the national opera performances and performances, is conducive to the students more quickly master the skills of national vocal music. The practice of Chinese national opera is closely related to the teaching of national vocal music. It is very important and necessary to integrate the practice of domestic opera into the teaching of national vocal music.

\section{Analysis on the present situation and problems of Chinese vocal music teaching in universities in China}

After decades of development, the national vocal music teaching in colleges and universities of our country has made great progress, and accumulated a wealth of teaching experience. Although the federal vocal music teaching in our country is becoming more systematic, standardized and mature, there are still many problems.

1.1 Students uneven quality.

With the reform of the educational system in China, China's colleges and universities to expand enrollment, in order to promote social employment. Therefore, the scale of enrollment, enrollment standard reduced, a direct result of some quality level is low, low level of ability of the students into the University, the students of national vocal music is poor, lack of solid professional knowledge, in school learning is not practical, enterprising, seriously affecting the quality of teaching of national vocal music.

1.2 Teachers lack of holistic teaching.

National vocal music is based on the singing skills, rather than relying solely on singing, but also to emotional expression and artistic accomplishment of the display, in order to perfect the essence of national choral music to the audience [2]. Therefore, teachers in the process of national vocal music 
teaching, not only to pay attention to the cultivation of students' basic form of singing, but also to strengthen the expression for the work of emotional and artistic form in-depth explanations, to deepen students' understanding of national vocal music.

1.3 Students lack of appreciation of works.

The significance of the appreciation of the works is to enable students to understand the essence of national vocal music, grasp the expressive and artistic style. Therefore, teachers in the teaching process of national vocal music, National Opera and folk songs should be the classic works into the classroom, students show, let students understand the works of different styles and embodied in the art form, and then strengthen the students for the classic works of vocal music practice, so as to strengthen students' understanding of the work and understanding. To improve the overall level of students of ethnic vocal music. However, at present, many colleges and universities pay attention to the teaching of domestic vocal music, but ignore the appreciation of classical folk opera and folk songs.

1.4 Students lack of understanding of domestic vocal music.

Despite the fact that more and more students begin to learn the national vocal music, they lack the correct understanding in the process of learning national vocal music. Many students use a number of foreign singing, while ignoring some of the things, which led to the essence of national vocal music cannot be truly understanding and understanding of [3]. Many students believe that the western classic should be the essence, impeccable, while neglecting the advantages of our national vocal music. As a result, it is bound to be detrimental to students' comprehensive study of nationwide vocal music.

\section{2 .The relationship between the National Opera practice and the national vocal music teaching in Colleges and Universities}

At the present stage, vocal music teaching in colleges and universities of our country is constantly innovating and improving. In the face of many problems, colleges and universities should take effective measures, will be integrated into the China National Opera practice to University of national vocal music, the Chinese national opera works show, let the students taste China National Opera charm, feelings of national vocal music feast of the hearing, make students understand Chinese national vocal music, to deepen understanding of Chinese national vocal music and make students more interested in learning China national vocal music, to devote more time and energy on studying Chinese national vocal music. Therefore, in the national vocal music teaching in the integration of Chinese national opera, we must fully understand the relationship between the practice of Chinese national opera and national vocal music teaching.

The purpose of college vocal music teaching is to inherit and carry forward the national culture, and for the community to cultivate outstanding national vocal music talent, China's national choral music to carry forward [4]. The China National Opera practice into Chinese national vocal music teaching, not only can effectively promote Chinese promote the dissemination of national culture, but also makes the Chinese National Opera in the performing arts form towards a new stage. Chinese national opera is closely linked to Chinese national vocal music teaching. The practice of Chinese national opera is beneficial to the teaching of domestic vocal music. In view of the existing problems at the present stage of our national vocal music teaching, the teaching process should Chinese National Opera into the national vocal music, the "Xiao either marriage", "Honghu Lake" and other national opera study and appreciation of national vocal music works in learning, students can deepen to the ethnic and national vocal music artistic charm the opera, so that the students can actively learn China national vocal music. The national opera to promote the teaching of national vocal music teaching, improve students' level of national vocal music, strengthen students' knowledge and understanding of national opera art and its expression form, promote students to become qualified talents of ethnic vocal music.

\section{The importance of Chinese National Opera practice in college vocal music teaching.}

Through the analysis and understanding of the relationship between the Chinese national opera and the national vocal music teaching, the practice of Chinese national opera is very important and necessary in the national vocal music teaching in colleges and universities. 
3.1 The practice of Chinese national opera is the driving force of the development of domestic vocal music teaching.

Chinese national opera and Chinese national vocal music teaching complement each other and promote each other. The development and progress of the Chinese national opera have promoted the systematization and standardization of the national vocal music teaching, and the continuous development of national vocal music has promoted the progress and innovation of Chinese National Opera [5]. The development of Chinese national opera has been closely related to the nationalized vocal music. The daughter of the party "this classic national opera for having heard it many times, I believe various selections which everyone can skilled singing out. The daughter of the party "as China's national opera classic, the art form has reached a certain height, it comes from life, but higher than life, combined with a variety of art forms, the use of folk opera, rap performances, praised the great spirit of the people and Chinese for fighting spirit of national liberation, at the same time describes the China people in China under the leadership of the Communist Party, arduous process with the enemy bravely struggle, to promote China's national vocal music has been developing rapidly. In addition there are many classic folk opera, such as "Liu Hulan", "white haired girl" and so on, the development of the National Opera Concert features and artistic style of their own, through the national vocal music to express its artistic form. Many of the classic folk opera into the interpretation of the federal vocal music, so that its artistic charm becomes more powerful [6]. It also shows that the relationship between Chinese folk opera and national choral music is very close. With the progress of the times and the progress of the society, people's understanding of the national culture is more profound, the cause of our country has been rapid development, so the development of national vocal music has also been promoted. In twentieth century five, 60s, the classic "Honghu National Opera" Red Guards creative fusion of opera, rape art and folk music, folk music has been fully displayed and expressed in this work. There are many classic national opera has been selected for various teaching materials, such as "sister Jiang", "Xiao either marriage", "the daughter of the party" and so on. National vocal music achievement is more and more significant, University of national vocal music teaching more and more attention, many colleges and universities began to set up a professional course of national vocal music, national vocal music teaching in China is gradually mature, let teaching become more standardized, more scientific and rational [7]. To sum up, China's national opera needs to be widely practiced and popularized in college vocal music teaching.

3.2 The practice of Chinese national opera is helpful to cultivate the compound talents.

Although at present many universities have put our national opera into the practice teaching of national vocal music, but the actual situation, China's national opera and national vocal music practice effectively without a combination of teaching, the national opera art style and form of expression can not truly be heritage and development, which is not conducive to the opening of national vocal music teaching also, can not truly cultivate talents for the society. The relationship between national opera and national raucous music is inseparable. The practice of national opera is helpful to improve the development of nationwide vocal music teaching and to cultivate the compound talents for the society. In view of the current situation of domestic vocal music teaching, it is very important to establish a standardized, scientific, effective and sound national opera practice and national vocal music teaching system [8]. Through the National Opera practice activities, strengthen the students' understanding of the origin and development of national opera, enhance students' understanding of the classic national opera classic works and aria, enhances the student to the classic works of art and stage characters, more solid for students to master in national vocal music learning, more solid basic skills. As for the normative, scientific, effective and sound national opera practice and the establishment of domestic vocal music teaching system, we must do two [9]. First, the basic knowledge of national opera and national vocal music must be solid. According to the college students for the national vocal music to grasp the situation and the actual situation in the teaching of national vocal music, choose some classical or Folk Opera repertoire, combined with the classic National Opera practice solutions through the basic theory about, vividly convey the artistic charm of national vocal music to students. Secondly, students should carry on the systematic teaching 
and practice the national opera. The students only learn National Opera and national vocal music theory is not enough, in order to understand the national opera, interspersed with classic National Opera teachers need to practice in the national vocal music teaching, such as "white haired girl", "Honghu Lake", "the daughter of the party" and other classic aria, constantly practice can improve students for the different national vocal music knowledge, national opera art style is conducive to enhancing the understanding level of national vocal music.

\section{Concluding remarks}

Chinese National Opera practice and national vocal music teaching complement each other, promote each other, common development and common prosperity. The development of Chinese National Opera makes the domestic vocal music teaching become standardized and scientific. The growth of national vocal music has promoted the continuous development of Chinese national opera. The two relations are inseparable [10]. Therefore, at this stage there are many problems in the universities of our country in the national vocal music teaching situation, universities and teachers should actively take measures to integrate our national opera and national vocal music teaching practice, in order to carry out national opera practice course Chinese teaching students through the practice of national opera to promote national vocal music theory knowledge explain, classic national opera works show for the students and to appreciate the classic of the national opera, various national opera classic songs for students and the corresponding national vocal music practice. These national opera practice allows students to master the basic theoretical knowledge of national choral music on the basis of more in-depth study and understanding of national vocal music, and constantly improve the level of national vocal music.

\section{References}

[1]Whittall A. Review: Britten, Voice and Piano: Lectures on the Vocal Music of Benjamin Britten[J]. Notes, 2005, 61(3):494-497(4).

[2]Valenti C. The Italian Traditions and Puccini: Compositional Theory and Practice in Nineteenth-Century Opera. By Nicholas Baragwanath.[J]. Music \& Letters, 2013, 94(4):689-690.

[3]Whittall A. Britten on Music/Britten, Voice And Piano: Lectures on the Vocal Music of Benjamin Britten (Book)[J]. Music \& Letters, 2004, 85(3):494-497(4).

[4]Butler M R. Pagodas in Play: China on the Eighteenth-Century Italian Opera Stage. By ADRIENNE WARD. Lewisburg, PA: Bucknell University Press. 2010. 232 p. \$80 (hb). ISBN 978-0-8387-5696-6[J]. Journal for Eighteenth-Century Studies, 2013, 36(1):149 - 150.

[5]Smith M W. Vocal Apparitions: The Attraction of Cinema to Opera (review)[J]. Opera Quarterly, 2006, 22(1):170-172.

[6]Basini L. Vocal Apparitions: The Attraction of Cinema to Opera. By Michal Grover-Friedlander. pp. xiv + 186. Princeton Studies in Opera. (Princeton University Press, Princeton and Oxford, 2005, £21.50. ISBN 0-691-12008-0.)[J]. Music \& Letters, 2006, 87(4):683-685.

[7]Johnson S. Britten, Voice and Piano: Lectures on the Vocal Music of Benjamin Britten, by Graham Johnson[J]. Notes, 2004, 61(3):494-497(4).

[8]Sousa N B D, Mello E L, Silva M A D A E. Feminine voice in the opera of Jules Massenet: Vocal characteristics and adjustment[J]. Musica Hodie, 2010, 10(1):69-80.

[9]Seletsky R E. The Performance Practice of Maria Callas: Interpretation and Instinct[J]. Opera Quarterly, 2004, 20(4):587-602.

[10]Parrott A. Review: Performance Practice of the Instrumental-Vocal Works of Johann Sebastian Bach[J]. Music \& Letters, 2004, 85(4):629-631(3). 